\title{
Comparative study with ranitidine and cimetidine on gastric secretion in normal volunteers ${ }^{*}$
}

\author{
K-FR SEWING†, A BILLIAN, AND H MALCHOW \\ From the Department of Pharmacology and Medical Clinic (Department I), University of \\ Tübingen, West Germany
}

SUMMARY The inhibitory effect of ranitidine and cimetidine on pentagastrin stimulated volume, acid and pepsin secretion has been studied in eight healthy volunteers. Both compounds inhibit all measured components of gastric secretion in a dose dependent manner. On a molar basis ranitidine is on average 11.14 times for volume, 13.04 times for acid, and 9.74 times for pepsin secretion more potent than cimetidine as measured by the $\mathrm{ID}_{50}$-values.

Ranitidine has been shown to be a specific and effective histamine $\mathrm{H}_{2}$-receptor antagonist in the standard systems. ${ }^{1}$ It has also been shown to be a potent inhibitor of gastric acid secretion in man..$^{2-5}$ Therefore ranitidine, like cimetidine, is a potential therapeutic agent in peptic ulcer disease; however, its therapeutically effective dose compared with that of cimetidine is not known. It was the purpose of the present investigation to study the dose response relationship of ranitidine and cimetidine in inhibiting gastric acid and pepsin secretion in man.

\section{Methods}

The experiments were done in eight healthy male volunteers aged 26.3 $\pm 1 \cdot 4$ years (range 20-31 years) and weighing $67 \cdot 4 \pm 2 \cdot 2 \mathrm{~kg}$ (range $61-79 \mathrm{~kg}$ ). The protocol was approved by the ethical committee of the medical faculty of the University of Tübingen, and written informed consent was obtained from each individual. The protocol was as follows: after an overnight fast a nasogastric tube was placed into the stomach and the correct position was tested by repeated suction. Gastric secretion was collected in 15 minute periods for 240 minutes by an automatic suction device (Gastrovac, Fa. Hirtz). Volume was measured to the nearest millilitre, acidity was determined by auto-

\footnotetext{
*Supported by a grant from Glaxo Group Research Ltd., Ware, England.

†Address for correspondence: Prof. Dr K-Fr Sewing, Abtlg. Allgemeine Pharmakologie, Medizinische Hochshcule, Hannover, Karl-Wiechert-Allee 9, D-3000 Hannover 61, West Germany.

Received for publication 26 February 1980
}

matic titration against $0.1 \mathrm{~N}$ sodium hydroxide (Autoburette Radiometer, Copenhagen), and pepsin content by Berstad's method ${ }^{6}$ using bovine pepsin as standard. Acid output is given as $\mathrm{mmol} \mathrm{H}^{+} / 15 \mathrm{~min}$ and pepsin output as $\mathrm{mg}$ pepsin/15 min if not otherwise stated. After a basal 60 minute period gastric secretion was stimulated by an intravenous infusion of $6 \mu \mathrm{g} / \mathrm{kg} / \mathrm{h}$ pentagastrin for three hours. After one hour of pentagastrin infusion cimetidine $(25,50,100$, or $200 \mathrm{mg})$ or ranitidine $(2 \cdot 5,5 \cdot 0,10 \cdot 0$, or $20.0 \mathrm{mg}$ ) was injected intravenously. Thus, the secretory tests were repeated nine times in each subject in a randomised order, one test serving as a control without injection of either cimetidine or ranitidine. Between each test at least three days elapsed. The dose response curves in each individual subject were constructed from the second and third period after injection of the inhibitor normalised as percentage of the corresponding periods of the experiment in which no inhibitor was injected. Each point represents the mean \pm SEM of one experiment in each subject. From these dose response curves the ID $_{50} \mathrm{~S}$ with their confidential limits were calculated. The dose response curves were tested for parallelism by the method of Cavalli-Sforza. ${ }^{7}$ Blood samples were drawn before the first and last secretory test for haematology and blood chemistry in order to detect adverse reactions.

\section{REAGENTS}

Pentagastrin (Gastrodiagnost, Merck, Darmstadt) $500 \mu \mathrm{g} / 2 \mathrm{ml}$; cimetidine (Tagamet, Smith Kline \& Dauelsberg, Göttingen) $200 \mathrm{mg} / 2 \mathrm{ml}$; ranitidine$\mathrm{HCl}$ (kindly supplied by Glaxo Group Research Ltd., Ware) $10 \mathrm{mg} / \mathrm{ml}$. Pepsin 100 units/g (Merck, 

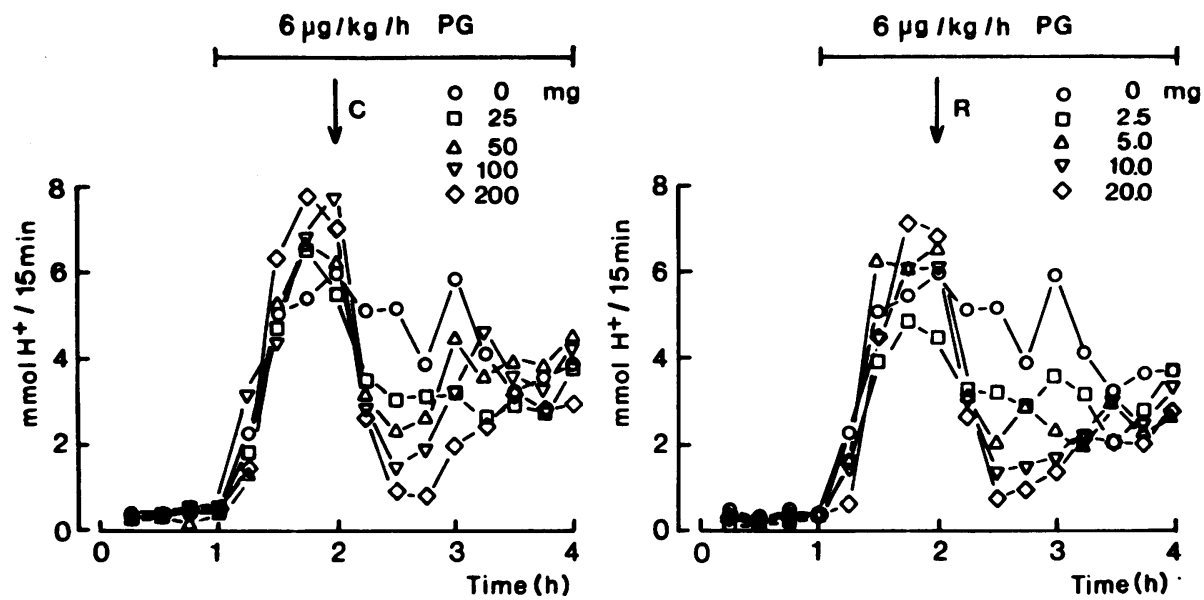

Fig. 1 Mean values of acid secretion of eight healthy volunteers in response to pentagastrin (PG) and after inhibition by different doses of cimetidine $(C)$ and ranitidine $(R)$.

Darmstadt). Haemoglobin was prepared in our own laboratory according to the prescription given by Berstad (1970).

\section{Results}

Basal secretion of all secretory tests as calculated by adding all four periods and dividing them by two was: volume: $16 \cdot 4 \pm 3.2 \mathrm{ml} / 30 \mathrm{~min}$; acid: $0 \cdot 6 \pm 0 \cdot 2$ $\mathrm{mmol} \mathrm{H}^{+} / 30 \mathrm{~min}$; pepsin: $13 \cdot 7 \pm 3.4 \mathrm{mg} / 30 \mathrm{~min}$. Pentagastrin-stimulated secretion reached a plateau after 30 minutes of stimulation. Therefore only the

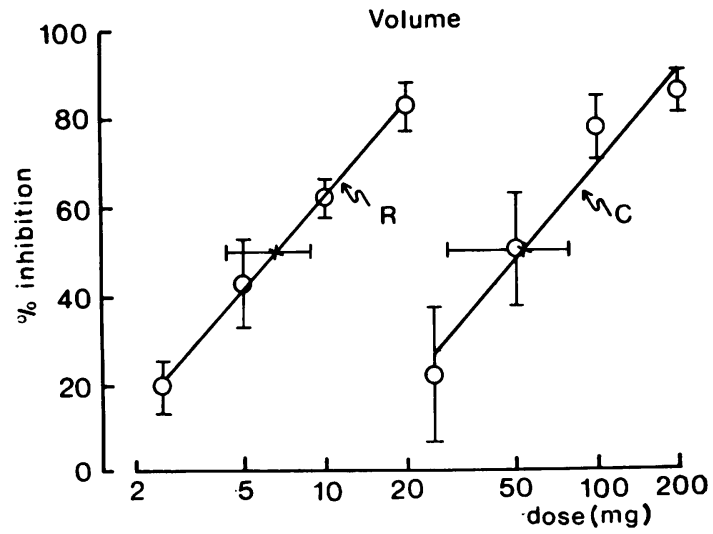

Fig. 2 Dose response curves of ranitidine $(R)$ and cimetidine $(C)$ for inhibition of pentagastrin stimulated gastric volume secretion in eight healthy volunteers. Values: mean $\pm S E$. The horizontal bars represent the calculated $I D_{50} s \pm 95 \%$ confidential limit.

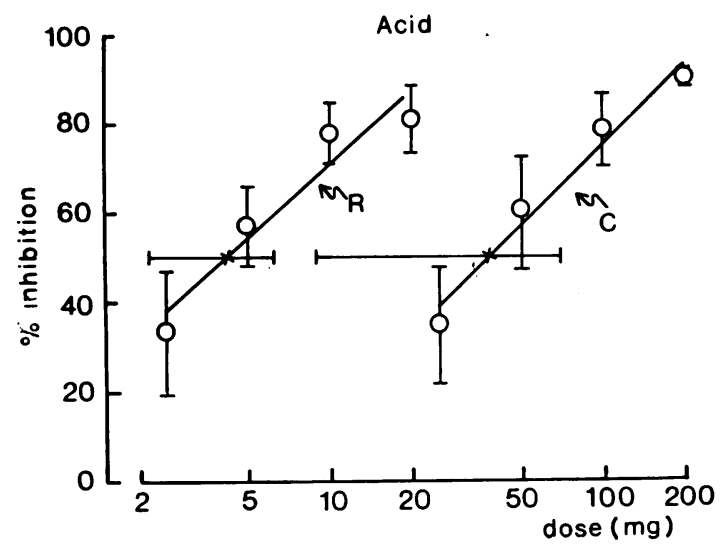

Fig. 3 The same as in Fig. 2 for acid secretion.

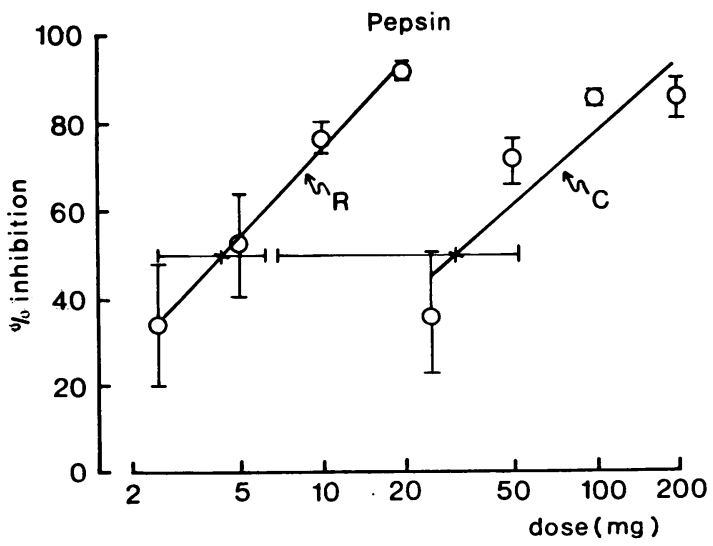

Fig. 4 The same as in Fig. 2 for pepsin secretion. 
last 30 minutes of the first pentagastrin hour were evaluated: volume: $98 \cdot 1 \pm 4.7 \mathrm{ml} / 30 \mathrm{~min}$; acid: $12.6 \pm 0.6 \mathrm{mmol} \mathrm{H}^{+} / 30 \mathrm{~min}$; pepsin: $63 \cdot 2 \pm 3 \cdot 7$ $\mathrm{mg} / 30 \mathrm{~min}$. There was a slight fading in secretion during the following two hours in most of the subjects; this is a well-known phenomenon.

Both histamine $\mathbf{H}_{2}$-receptor antagonists caused a dose dependent inhibition of volume, acid and pepsin secretion in the range of the doses tested. Acid response to pentagastrin and its inhibition by ranitidine and cimetidine is representative for the secretory pattern of the other two variables (volume and pepsin secretion). Therefore the mean values of acid secretion in response to pentagastrin and to the doses of ranitidine and cimetidine tested are shown in Fig. 1. The dose response curves (Figs. 2-4) as calculated for each individual subject did not differ significantly from being parallel. The $\mathrm{ID}_{50} \mathrm{~S}$ with their $95 \%$ confidential limits on a weight basis are as follows for ranitidine: volume $6.68 \pm 2.32 \mathrm{mg}$, acid $4.24 \pm 2.04 \mathrm{mg}$, and pepsin $4.40 \pm 1.86 \mathrm{mg}$; for cimetidine: volume $53.63 \pm 25.16 \mathrm{mg}$ and $39.60 \pm$ $30.68 \mathrm{mg}$, pepsin $30.70 \pm 23.82 \mathrm{mg}$. From the data the following molar ratios of potency for the three variables can be calculated: volume 11.14 (range 1.41-14.70), acid 13.09 (range 1.78-19.19), pepsin 9.74 (range $0.71-11.61$ ). From the recovery time there was no indication for a difference in the duration of action between the two drugs.

At the beginning and at the end of the study laboratory data were within the normal range.

\section{Discussion}

The results have shown that ranitidine and cimetidine both effectively inhibit pentagastrin-stimulated volume, acid and pepsin secretion in normal volunteers. From the normalised data a parallel dose response relationship for all three secretion variables is evident. The relative potencies of both drugs as calculated from $\mathrm{ID}_{50} \mathrm{~s}$ differ from those published so far. ${ }^{23}$ This is probably because in none of the studies dealing with dose comparison was a dose response relationship over a wide submaximal range of both drugs established. All secretory components (fluid, acid, and pepsin) were almost equally affected by both drugs in their effective dose range. From the present study no conclusions can be drawn as to whether the two drugs differ in the extent of maximal inhibition they can produce: that is worth another study. From the time that has to elapse between maximal inhibition and recovery it looks as if there is no difference between the two drugs. That would reflect the almost identical half lives of both drugs. It has to be emphasised that, in this study, both compounds were given intravenously as a bolus injection. If the drugs differ in their bioavailability it might be necessary to correct the dose of ranitidine for oral administration according to these differences.

The skilful technical assistence of Miss E Keppler is gratefully acknowledged.

\section{References}

${ }^{1}$ Glaxo-Allenburys Research (Ware) Ltd. AH-19065, histamine- $\mathrm{H}_{2}$ receptor antagonist. Clinical investigators manual 1978; B1-9.

${ }^{2}$ Domschke W, Lux G, Domschke S. Gastric inhibitory action of $\mathrm{H}_{2}$-antagonists ranitidine and cimetidine (letter). Lancet 1979; 1 : 320.

${ }^{3}$ Hagenmüller $\mathrm{F}$, Zeitler-Abu-Ishira $\mathrm{A}$, Classen $\mathbf{M}$. Hemmung der Magensäuresekretion durch den Histamin $\mathrm{H}_{2}$ Rezeptorantagonisten AH-19065 (Ranitidine) im Vergleich zu Cimetidine-eine Doppelblindstudie (abstract). Z Gastroenterol 1979; 17: 583

${ }^{4}$ Peden NR, Saunders JHB, Wormsley KG. Inhibition of pentagastrin-stimulated and nocturnal gastric secretion by ranitidine. Lancet $1979 ; 1$ : 690-2.

${ }^{5}$ Simon B, Göttling E, and Kather H. Ranitidin: Ein potenter oral wirksamer Hemmer der menschlichen Säuresekretion (abstract). Z Gastroenterol 1979; 17: 582.

${ }^{6}$ Berstad A. A modified hemoglobin substrate method for the estimation of pepsin in gastric juice. Scand $J$ Gastroenterol 1970; 5: 343-8.

'Cavalli-Sforza L. Biometrie, Grundzüge biologischmedizinischer Statistik. Stuttgart: Gustav Fisher Verlag, 1969. 